\title{
Las Becas viajeras
}

\author{
The travelling fellowship experience \\ Valero-González FS*
}

Hospital Ángeles Pedregal CDMX.

En el proceso de mejorar la calidad de la oferta académica y la capacitación del cirujano ortopedista en cualquier momento de su formación y desempeño, la evolución del proceso de enseñanza-aprendizaje en el individuo adulto ya graduado y con una especialidad se encuentra muy lejana del modelo de clases magistrales en desuso, en la mayoría del mundo académico moderno, pero que aún tiene algunos promotores dentro de nuestro medio. En la actualidad, lo importante es incorporar el recurso médico al mundo laboral, pero permitiendo el acceso a modelos de aprendizaje modernos, que han demostrado un cambio positivo en la práctica profesional.

En la segunda mitad del siglo pasado surgió la inquietud en algunas universidades europeas y americanas de ofrecer la oportunidad a algunos médicos de exponerse a la práctica de la medicina en el mundo. El concepto partía del supuesto de que, al exponer al candidato a la práctica de su área de preferencia, se podría establecer un punto de comparación con su ámbito habitual, y ello le permitiría exponerse a diferentes formas de pensar que pudieran contrastar sus fortalezas y reevaluar sus debilidades. Bajo este esquema, diferentes instituciones fundaron sus «Becas viajeras» (travelling fellows) destacando, entre ellas, la Universidad de Harvard.

En el Área Ortopédica estas experiencias surgieron de igual forma y dieron paso a programas de intercambio o estancias entre diferentes programas universitarios de la especialidad. Sin embargo, a partir del interés de la industria de implantes ortopédicos en la enseñanza, estos viajes alcanzaron el grado internacional. Aunque de forma obvia estos viajes tenían como principal objetivo exponer a los médicos a la tecnología propia de dicha empresa, el viaje era realmente una experiencia mercadológica y académica combinada. Este modelo actualmente se mantiene, pero ya con un enfoque claro de capacitación en técnicas específicas de una empresa determinada.

* Profesor Titular del Curso de Alta Especialidad en Cirugía de Reconstrucción Articular de Hombro y Codo. Facultad Mexicana de Medicina de la Universidad La Salle, Hospital Ángeles Pedregal, Grupo Ángeles Servicios de Salud.

Este artículo puede ser consultado en versión completa en: www.medigraphic.com/actaortopedica
Finalmente, este proceso llegó a ser motivo de interés por parte de algunas de las sociedades médicas de la especialidad. Así, en la actualidad existen estos programas en: AOSSM (American Orthopedic Society for Sports Medicine), AANA (Arthroscopic Association of North America), ESSKA (European Society of Sports Traumatology, Knee Surgery \& Arthroscopy), APKASS (Asia Pacific Knee, Arthroscopy and Sports Medicine Society), entre otras. También se han desarrollado programas de becas viajeras entre estas sociedades y, en las últimas dos décadas, se han realizado programas que incluyen a sociedades locales o regionales, como ha sido el caso de AMECRA (Asociación Mexicana de Cirugía Reconstructiva Articular y Artroscopía) y SLARD (Sociedad Latinoamericana de Artroscopía, Rodilla y Deporte). AMECRA ha sido anfitrión de los programas de AOSSM desde el 2006, ESSKA en 2011 —en aquella ocasión al frente del Dr. C Niek van Dijk de los Países Bajos y los Dres. Giuseppe Longo de Italia, Pablo Gelber-Gerthner de España y Alessandro Russo de Italia-. En 2015, AMECRA fue anfitrión del Travelling Fellow de la APKASS, con el Dr. Eiji Itoi de Japón, al frente del grupo y los Dres. Lu Yi de China, Yong Seuk Lee de Corea del Sur y Warren Leigh de Nueva Zelanda.

En esencia, las becas viajeras o travelling fellows se fueron modelando de forma que los objetivos de éstas se pueden reducir a:

1. Exponer a los médicos seleccionados con otra forma de pensar y otra forma de llevar la práctica de la especialidad.

2. Para llevarlo a cabo se selecciona a un líder de opinión, quien funge como el director de viaje y coloquialmente es llamado «Godfather». Los requisitos para poder formar parte de los beneficiados de esta experiencia varían de acuerdo con cada Sociedad o Asociación; sin embargo, algo importante es que cada uno debe ser capaz de expresarse en inglés y debe preparar una exposición acerca de algún tema que domine o tenga experiencia para cada uno de los puntos del plan de viaje. La edad depende de cada organización, pero en general se sugiere que el aspirante tenga una formación en alguna área más allá de la especialidad y deba presentar una carta intensión que exponga los motivos del candidato para realizar el viaje. 
3. El objetivo es que el médico no nada más se exponga a los médicos del sitio que visita, sino que sus anfitriones también reciban una muestra de lo que estos médicos realizan en su lugar de procedencia. De esta forma, la beca viajera adquiere un aspecto vivencial que enriquece la experiencia del médico con relación al balance final de la misma.

Mi opinión acerca de estos programas, desde el ángulo de haber participado de forma personal en los tours organizados por las casas comerciales a finales de los ochenta, pasando por las estancias patrocinadas por las casas comerciales para la promoción de sus productos, hasta la versión actual de las becas viajeras, en las que me ha tocado participar como un facilitador y como anfitrión para que mexicanos acudan a ellas, es que estas experiencias modelaron mi práctica y desarrollo profe- sional al permitirme interactuar de forma directa con cirujanos americanos y europeos, líderes en sus áreas de interés.

Hay que considerar que también esta herramienta tiene sus aristas; se requiere el dominio del inglés, disponer de tiempo ya que tienen una duración entre dos y tres semanas; requiere la habilidad de exposición y discusión con un alto nivel basado en la experiencia, por lo que consideró que los médicos con menos de cinco años de egresados no son buenos candidatos.

Estos procesos deben ser mejor difundidos para que un mayor número de colegas nacionales puedan aspirar y optar por ellas. Al mismo tiempo que considero que nuestras instituciones nacionales y regionales cuentan con los recursos económicos y estructura humana suficiente para iniciar su propio programa de becas viajeras. 